\title{
KONTEMPORER FINISHING PADA MEDIA GERABAH NON SILIDRIS DENGAN TEKNIK PAINTING IN THE WATER
}

\author{
Arif Suharson \\ Dwita Anja Asmara *)
}

\begin{abstract}
Creative terracotta products are required to meet the best possible standard of material, technique, and finishing method. Innovation in the shapes and finishing application of non-cylindrical terracotta products can be an appropriate solution to crease centre of interest, and to meet the need for contemporary and modern terracotta products in the market. Most of the artisans of terracotta products have not diversified their products. Neither have they made innovation about the design for non-cylindrical terracotta products for interior or exterior ornaments. The finishing of products has not improved due to the minimal knowledge in the composition of color and technique.

This study is an applied research to identify the innovation in shapes of non-cylindrical terracotta products and the quality of terracotta art products. Finishing is the last step in the process of production. It has to be in harmony with the contemporary design and trend in order to increase the price of products. This study specifically found the finishing composition with the method of painting in the water the process of which is performed in the water to result in unique and artistic color combination.

Products of the creative industry of terracotta have attracted both domestic and international consumers' attention. Innovation in non-cylindrical shapes and application of contemporary finishing technique of painting in the water will be attractive and beneficial in improving the quality of terracotta productions in global market era. Therefore, they can result in superior advantages that lead to the increase of economic welfare especially for those involved in creative works of terracotta.
\end{abstract}

Key words: finishing, terracotta, product, creative, technique

ABSTRAK

Produk-produk kreatif seni gerabah terracotta dituntut mampu memenuhi standar kualitas baik dari segi, bahan, teknik, dan finishingnya. Inovasi bentuk gerabah non silindris dan aplikasi finishing mampu menjadi solusi yang tepat untuk membuat centre of interest, dan mengarah pada pemenuhan kebutuhan gerabah kontemporer atau modern, sehingga dapat memenuhi keinginan pasar. Kalangan pengrajin banyak yang belum melakukan diversifikasi dan inovasi desain bentuk gerabah non silindris yang difungsikan sebagai elemen seni hias

*) Arif Suharson (arifkeramos@yahoo.com), Staf Pengajar Program studi Kriya Seni, Jurusan Kriya, Fakultas Seni Rupa, Institut Seni Indonesia Yogyakarta.

Dwita Anja Asmara (9putriarca@gmail.com), Staf Pengajar Program studi Kriya Seni, Jurusan Kriya, Fakultas Seni Rupa, Institut Seni Indonesia Yogyakarta. 
interior/eksterior. Finishing produk gerabah juga mengalami kendala dan seolah hanya pasrah dengan finishing yang ada, dikarenakan minimnya pengetahuan dalam mengkomposisikan warna dan teknik finishing baru yang dianggap sulit.

Penelitian ini merupakan penelitian terapan yang mengarah pada inovasi bentuk produk gerabah non silindris dan pencapaian mutu finishing pada produk seni gerabah terracotta. Finishing merupakan teknik akhir dalam menyelesaikan produk agar menjadi lebih baik, menyelaraskan dengan trend desain terkini, dan mampu mengangkat harga jual suatu produk. Penelitian ini akan menemukan komposisi finishing dengan metode painting in the water. Dimana proses pelaksanaan finishing gerabah dilakukan dalam air dengan hasil finishing kontemporer dengan perpaduan warna yang unik dan artistik.

Produk-produk dari dunia industri kreatif terutama seni gerabah terracotta mulai banyak diminati oleh konsumen, baik dari dalam negeri maupun luar negeri. Inovasi bentuk gerabah non silindris dan aplikasi finishing kontemporer dengan teknik painting in the water akan menjadi salah satu daya tarik dan mampu meningkatkan mutu produksi seni gerabah terracotta yang akan memberikan dampak kemajuan pada seni tradisional di era pasar global. Sehingga mampu memberikan keunggulan yang berdampak pada penghasilan ekonomi kesejahteraan, terutama bagi insan dunia kreatif pada bidang seni gerabah terracota.

Kata kunci: finishing, gerabah terracotta, produk, kreatif, teknik

\section{PENDAHULUAN}

Produk-produk seni gerabah yang selama ini diproduksi oleh pengrajin di wilayah Jawa kebanyakan dibuat dengan teknik putar. Dari hasil teknik putar ini produk-produk yang dihasilkan berwujud silindris, seperti kendi, pot bunga, vase, gentong, guci, teko, piring, dan masih banyak lagi produk gerabah silindris yang biasanya digunakan untuk pemenuhan kebutuhan peralatan rumah tangga. Produk-produk tersebut biasanya difinishing secara tradisional yaitu dengan cara membakar dua kali atau ngireng yang menjaga kemurnian tanah agar tetap bersih atau tidak terkontaminasi dengan cat pabrikasi atau bahan yang lainnya.

Hal ini sangat beralasan karena produk gerabah yang difinishing secara alam akan memberikan dampak yang baik dan tidak mengganggu taste jika digunakan untuk produk fungsional praktis terlebih untuk wadah makanan/minuman. Finishing ngireng memang menjadi salah satu ciri khas dan memiliki sifat natural yang baik. Akan tetapi pangsa pasarnya mulai menurun dan menuntut diversifikasi produk gerabah yang dapat difungsikan sebagai elemen seni hias interior/ekterior sesuai kebutuhan masyarakat sekarang. Produk-produk gerabah kreatif tersebut juga dituntut memiliki warna-warna sesuai trend disain yang selaras dengan perkembangan zaman. Juga produk gerabah sudah merambah akan kebutuhan seni estetis interior maupun eksterior bahkan seni murni sebagai pemenuhan kebutuhan seni ekspresi murni/fine art.

Metode finishing painting in the water memang menjadi teknik yang baru 
dalam dunia finishing gerabah terracotta. Hasil finishing yang menyerupai goresan lukisan abstrak ini memang memiliki nilai artistik dan unik. Finishing ini harus dilakukan dalam bak air, dan proses pewarnaannya juga dalam air dengan beberapa warna. Hal ini membutuhkan keuletan dan penelitian yang kontinyu agar memperoleh hasil finishing yang baik dan sesuai dengan selera konsumen seni gerabah terracotta. Harmonisasi warna dan alur yang indah akan menonjolkan bentuk gerabah terracotta yang biasa menjadi memiliki nilai atau volume yang baik.

Finishing dengan metode painting in the water ini akan memberikan aksen ornamen kontemporer, sehingga produkproduk gerabah terracotta yang difinishing dengan metode ini akan tampak lebih bernilai dan bodi gerabah tradisional menjadi modern. Selain itu hasil produk gerabah dibuat non silindris dan finishingnya dibuat sesuai trend desain yang berkembang saat ini. Sehingga inovasi bentuk dan finishing dengan metode painting in the water akan memberikan dampak yang luas terhadap perkembangan finishing terutama produk-produk seni gerabah terracotta tradisional Indonesia. Dengan demikian produk seni tradisional kita yang memiliki ciri khas local genius akan tetap memiliki pangsa pasar yang baik, karena mampu memenuhi standar kualitas desain dan finishing sesuai trend desain.

\section{HASIL DAN PEMBAHASAN}

Lokasi penelitian ditetapkan di sentra gerabah Pundong dan Kasongan yang terletak di Kabupaten Bantul. Sentra gerabah Pundong terletak di desa
Panjangrejo, Pundong, dimana sentra ini terkenal dengan produksi gerabah silindris berukuran kecil atau sering disebut gerabah souveniran. Sedang desa Kasongan terletak di Desa Bangunjiwo, Kasihan yang merupakan salah satu desa wisata andalan di Kabupaten Bantul. Kedua sentra gerabah yang menjadi objek penelitian merupakan desa penghasil gerabah dengan suhu pembakaran rendah $500-800^{\circ} \mathrm{C}$ (earthanware).

Sentra gerabah Pundong dan Kasongan dipilih sebagai tempat penelitian karena memang kedua sentra sampai saat ini masih eksis berproduksi dan terus berkembang mengikuti selera pasar. Hasil finishing yang dihasilkan dari penelitian ini juga akan sangat membantu pengrajin gerabah untuk meningkatkan mutu finishing dengan produk gerabah-gerabah kreatif non silindris. Harapannya akan semakin membuat sentra gerabah Pundong dan Kasongan semakin dikenal pasar internasional, sehingga pertumbuhan perekonomian pengrajin juga bertambah maju dan produktif.

Penelitian ini dilakukan sebagai wujud sumbang sih dan kepeduliaan instansi pendidikan terutama ISI Yogyakarta yang memiliki Jurusan Kriya terutama Kriya Keramik untuk membantu kesulitan pengrajin dan mengembangkan produk seni gerabah terracotta terutama dalam hal inovasi desain produk non silindris dan finishing, terutama di sentra gerabah Pundong. Tidak hanya itu tuntutan konsumen tentang mutu produk dan desain-desain baru dapat diwujudkan. Selama ini produk gerabah terracotta yang dihasilkan oleh pengrajin gerabah tradisioanal bersifat monoton dan kurang 
inovasi. Belum ada keinginan pengrajin untuk membuat bentuk-bentuk yang inovatif dan membuat desain baru. Bahkan masih banyak produk terracotta yang dijual abangan atau hanya difinishing ngireng. Dapat dikatakan produk dijual masih dalam keadaan mentah dan belum difinishing, sehingga harganya lebih murah.

Penelitian ini juga akan memberikan manfaat teknis dan pengetahuan tentang finishing seni gerabah terracotta yang baik. Target yang lain adalah merubah pola pikir pengrajin bahwa melakukan finishing produk itu mudah dan mampu mengangkat harga jual produk gerabah menjadi lebih baik. Dengan gerabah yang difinising dengan baik akan meningkatkan niali jual harga gerabah yang berdampak langsung pada meningkatnya taraf hidup pengrajin gerabah tradisional..

Kendala finishing sesuai trend disain yang berkembang dan menjadi tuntutan pasar modern dapat teratasi. Metode ini akan mampu meningkatkan mutu dan kreasi pengrajin dalam membuat produk dengan ornamentasi yang berbeda. Hasil dari kegiatan Penelitian yang dilakukan akan menjadi pemicu semangat jiwa kreativitas pengrajin gerabah tradisional yang mampu menciptakan inovasi desain produk-produk kreatif non silindris dan melakukan inovasi teknik finishing produk gerabah, sehingga akan mampu meningkatkan ekonomi masyarakat penyangganya.

Perkembangan

produk kontemporer ikut mempengaruhi pula bentuk dan finishing yang diterapkan. Kevin A. Hluch dalam bukunya yang berjudul The Art of Contemporary
American Pottery (2001) yang menjelaskan tentang bagaimana membuat keramik yang tidak hanya terlihat baik, tetapi juga dengan aksen finishing yang akan membuat keramik lebih memiliki makna dan dapat difungsikan dengan baik dan benar. Buku ini sangat banyak memberikan contoh-contoh produk keramik fungsional modern dan kontemporer yang sedang berkembang di Amerika yang juga menjadi acuan trend disain dunia karena diambil dari seniman-seniman keramik terkenal di Amerika dan galeri-galeri keramik dari berbagai negara.
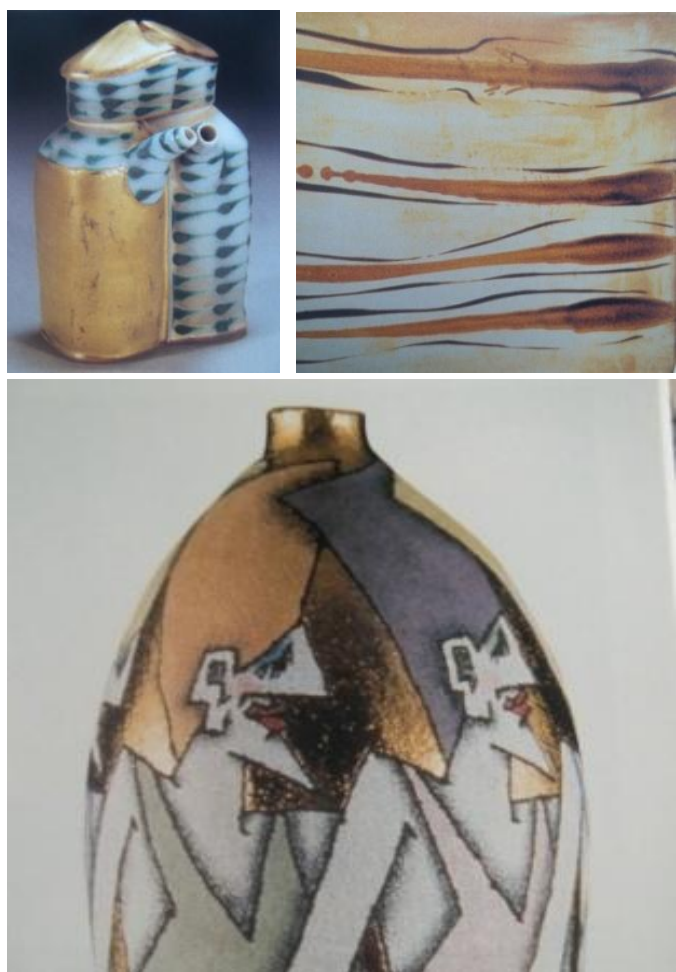

Gambar 1. Julia Galloway, Mackenzie Smith, Rimas Via Girda
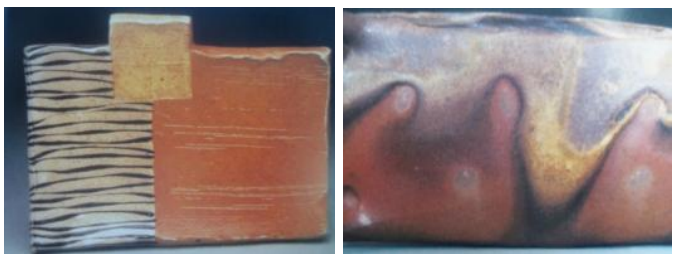

Gambar 2. Ashley Kim, Simon Levin 
Finishing kontemporer yang dilakukan dengan teknik painting in the water akan membuat out line garis memiliki irama dan membentuk ornament yang lembut. Hubungan dengan seni kontemporer yang ingin dicapai adalah sifat individu menjadi partisipatoris, memakai hal-hal yang bersifat tradisi sebagai bahasa symbol terhadap permasalahan kebudayaan, mencerminkan kebudayaan urban, dan kebudayaan pop serta bersifat multimedia, dapat memadukan rupa, gerak, perpaduan bahan, dan lain-lain (Fx. Harsono dalam Jurnal Seni edisi II/03-Juli 1992 yang berjudul "Perkembangan Seni Rupa Kontemporer Indonesia-Tinjauan Problematik").

Jim Supangkat dalam pengantar buku hasil penelitian Sumartono, Asmudjo Jono Irianto, Rizki A. Zaelani, M. Dwi Marianto, mengungkapkan pikiranpikirannya dalam Outlet; Yogya Dalam Peta Seni Rupa Kontemporer Indonesia bahwa Yogyakarta sebagai kontradiksi, dua alur perkembangan seni rupa modern Indonesia, tradisi modernis dan tradisi realis di Indonesia, paradigma seni rupa Indonesia, serta Yogyakarta dan seni kontemporer Indonesia. la mengemukakan bahwa pengertian seni rupa kontemporer tidak bisa dipahami tanpa mengkaji seni rupa modern. Bahwa seni rupa kontemporer pada dasarnya merupakan kontradiksi dengan seni rupa modern.

Jadi dalam penelitian ini finishing kontemporer yang dimaksudkan adalah pembuatan finishing dengan memadukan dua unsur bahan cat yang berbeda dengan teknik finishing yang berbeda yaitu mewarna di dalam air. Di dalamya ada penambahan unsur ornament tradisi budaya Indonesia yang dibuat modern dengan penggayaan atau stilisasi yang disesuaikan dengan bentuk-bentuk gerabah non silindris yang menjadi target penelitian. Dari itu timbullah berbagai macam bentuk, motif, dan pola ornamen segala variasi sesuai perkembangan dan tuntutan zaman. Secara jelas diperlihatkan beberapa motif seni ornamen daerah yang menjadi ciri khas daerah tersebut.

Penerapan ornamentasi tradisi dalam keramik modern dipandang perlu sehingga identitas lokal akan menjadi ciri produk yang tidak dimiliki oleh orang lain. SP. Gustami, dalam buku yang berjudul Nukilan Seni Ornamen Indonesia, menjelaskan betapa pentingnya ornamen dalam kehidupan seni. Hal ini dapat dilihat dari hasil ornamen yang diterapkan oleh penikmat seni dalam sendi-sendi kehidupan, baik itu bersifat jasmani atau pemenuhan kebutuhan rohani. Dari itu timbullah berbagai macam bentuk, motif, dan pola ornamen segala variasi sesuai perkembangan dan tuntutan zaman. Secara jelas diperlihatkan beberapa motif seni ornamen daerah yang menjadi ciri khas daerah tersebut. Penerapan ornamentasi tradisi dalam keramik modern dipandang perlu sehingga identitas lokal akan menjadi ciri produk yang tidak dimiliki oleh orang lain.

Proses pembuatan gerabah non silindris tersebut diawali dengan menyiapkan desain-desain alternatif yang didesain dengan melihat beberapa referensi yang kita kembangkan menjadi bentuk yang lebih baik dari segi bentuk dan fungsional praktisnya. Dari beberapa ide desain yang dibuat, kemudian dipilih 
desain yang terbaik untuk dijadikan produk jadinya. Produk jadi yang dibuat dari desain terpilih kemudian menjadi master desain yang akan dibuat cetakannya.

Cetakan dimaksudkan sebagai wahana untuk memperoleh produk yang tepat bentuk, tepat ukuran dan mempercepat proses produksi sesuai tuntutan pasar yang sekarang berkembang. Setelah proses mencetak dengan teknik reproduksi selesai dilakukan, proses selanjutnya adalah pengeringan produk gerabah. Produk-produk yang sudah jadi dikeringkan dengan cara menganginanginkan terlebih dahulu. Produk yang sudah jadi tidak langsung dijemur dengan sinar matahari, tetapi diangin-anginkan dahulu.

Proses pengeringan dilakukan secara perlahan-lahan agar produk yang dihasilkan tidak mengalami keretakan atau terlalu cepat terjadi perubahan yang mengakibatkan karya tersebut retak bahkan pecah. Proses pengeringan jika dilakukan secara mendadak dan langsung terkena sinar matahari otomatis akan terjadi perubahan bentuk yang cepat bahkan dapat terjadi pecah. Setelah semua bodi kering barulah dilakukan pengeringan langsung terkena sinar matahari agar kandungan air di dalam bodi keramik benar-benar habis sebelum dilakukan proses pembakaran. Jika pengeringan dianggap cukup proses selanjutnya adalah penataan produk di dalam tungku pembakaran. Proses ini merupakan proses yang sangat menentukan dan dibutuhkan pengalaman menata produk dalam tungku yang cukup.

Untuk itu produk khusus untuk penelitian ini diperlakukan seperti pembakaran keramik agar diperoleh hasil penelitian yang baik. Karena menggunakan pembakaran dengan tungku gas yang ada di studio keramik ISI Yogyakarta, proses pembakaran dapat dilakukan dengan terstruktur dan hasilnya dapat dilakukan pencatatan yang teratur pula. Setelah produk tertata dengan baik di dalam tungku, maka proses pembakaran dapat dilakukan. Setelah produk gerabah dibakar, kemudian target selanjutnya adalah membuat finishing. Finishing diawali dengan melakukan ekperimen-ekperimen terlebih dahulu agar hasil finishing dengan teknik painting in the water dapat menghasilkan finishing yang baik sesuai target penelitian.

Gerabah juga dapat dimaknai sebagai sebuah produk yang mengacu pada hasil benda berbahan tanah liat dengan pola penggarapan tradisi masa lalu yang statis dalam kurun waktu lama. Adapun keramik dimaknai sebagai hasil benda berbahan tanah liat yang telah mengalami perkembangan yang merambah pada perluasan perbaikan bentuk, fungsi, serta aplikasi teknologinya. Oleh sebab itu perkembangan keramik Indonesia banyak dipengaruhi oleh bagaimana memilih bahan, cara bakar, finishing, dan pemasarannya (Timbul Raharjo, Historis Desa Gerabah Kasongan, 2009)

Warna dapat mengungkapkan perasaan atau watak benda yang telah dan sedang dirancang. Warna juga memiliki sifat yang berbeda-beda serta variasi yang tidak terbatas. Klasifikasi warna berdasarkan sifatnya seperti warna tua, muda, terang, gelap, redup atau cemerlang. Sedangkan dari macamnya 
dapat digolongkan pada warna kuning, hijau, merah, jingga, dan lain sebagainya. Pengertian dari sifat warna adalah ciri khas suatu warna dibandingkan dengan warna lain. Sedangkan watak warna adalah kesan khas suatu warna yang berhubungan dengan perasaan. Peran warna dalam seni kerajinan gerabah tergolong penting karena berpengaruh besar pada nilai jual dan estetis yang berbanding lurus dengan trend desain dan perubahannya (Trend Disain 2013, Kementerian Koperasi dan UMKM RI, 2012).

Proses finishing kontemporer dilakukan bertahap pada produk-produk gerabah fungsional non silindris dengan tahapan sebagai berikut:

\section{Tahapan penghalusan gerabah bisquit dan} pendempulan

Yaitu proses pengamplasan gerabah dan penambalan produk gerabah dengan menggunakan bahan khusus dari grog + lem fox. Kedua bahan tersebut dicampur dengan komposisi 2 (grog) : 1 (lem) agar diperoleh komposisi yang baik untuk menambal bagian-bagian tertentu gerabah yang lubang, retak kecil, dan bagian yang tidak rata. Penambalan tidak boleh digunakan untuk menambal produk yang retak besar atau rusak berat. Pengahlusan gerabah juga bisa dilakukan dengan diamplas halus.

Gerabah kratif yang sudah difinishing painting in the water dan sudah diberi pola-pola tertentu, kemudian dilakukan teknik pendempulan. Pendempulan bertujuan untuk membuat gerabah kreatif tersebut memiliki warna lain untuk penguatan produk itu sendiri. Pendempulan diterapkan pada bidang- bidang gerabah yang tidak kita inginkan ada atau dengan kata lain menghapus sisa finishing in the water dengan semen putih ataupun cat yang disemprotkan langsung pada media gerabah. Maka terciptalah 10 desain gerabah kreatif fungsional non silindris sesuai out put penelitian.

\section{Tahapan finishing painting in the water}

Gerabah yang sudah diamplas halus kemudian dibersihkan dengan air agar debu tidak menempel dan gerabah benarbenar dalam keadaan bersih. Setelah itu dipersiapkan ember besar atau bisa juga mmbuat bak-bak penampungan air untuk proses finishing painting in the water. Juga disiapkan bahan-bahan cat untuk aplikasi finishing tersebut. Pembuatan finishingnya dilakukan dengan menggerak-gerakkan cat di dalam air sehingga membentuk gelombang-gelombang air yang diikuti oleh cat membentuk alur-alur warna.

Jika sudah pas dengan keinginan kita yaitu cat yang membentuk garis-garis dengan perpaduan warna yang baik, baru kita masukkan produk gerabah dengan mengankat dari bawah ke atas menuju perpaduan warna dan melekatkannya pada bodi gerabanya.

\section{Tahapan pemolaan dan oramentasi}

Finishing yang sudah dianggap berhasil kemudian dilakukan pengecekan dan dianalisis kira-kira bagian-bagian mana yang mau di ekpos untuk membuat ornamentasi. Sebelum ornamentasi dibuat, terlebih dahulu dilakukan pemolaan dengan membuat atau membagi bidangbidang tertentu yang dibentuk sesuai keinginan. Bisa berbentuk sulur-sulur, garis, bidang kotak, segitiga, lingkaran, dll. 


\section{Tahapan clearing dengan melamin (penguncian warna)}

Proses terakhir dalam pembuatan finishing agar terlihat rapi, halus, dan bercahaya maka, tahapan terakhir adalah dengan melapisi produk gerabah tersebut dengan melamin yang disemprotkan dengan spray gun. Jika produk belum terlihat glossy atau clear belum rata dapat diulang sampai memperoleh hasil yang maksimal.

Berikut akan ditunjukkan cara dalam membuat warna dan tahapan proses painting in the water pada gerabah kreatif hasil penelitian:

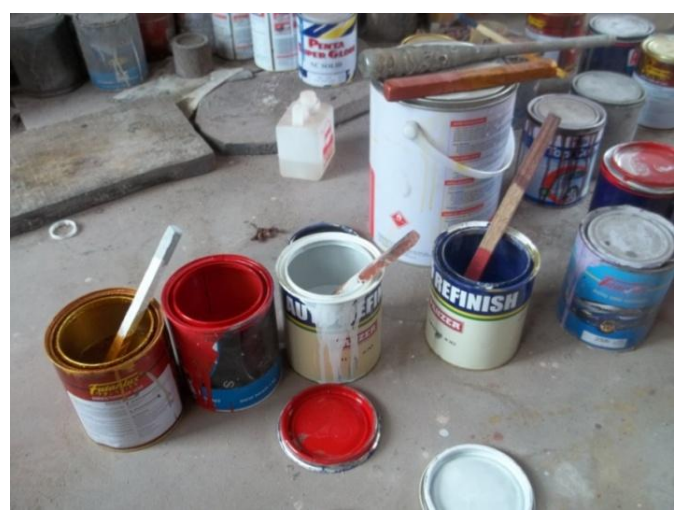

Gambar 3. Warna cat minyak disiapkan dan dibuat encer dengan alat kayu untuk menuang cat pada air

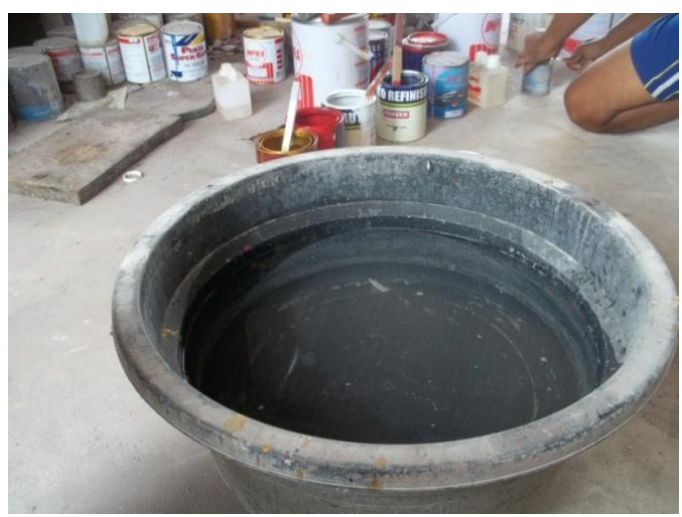

Gambar 4. Siapkan ember-ember besar yang beisi air

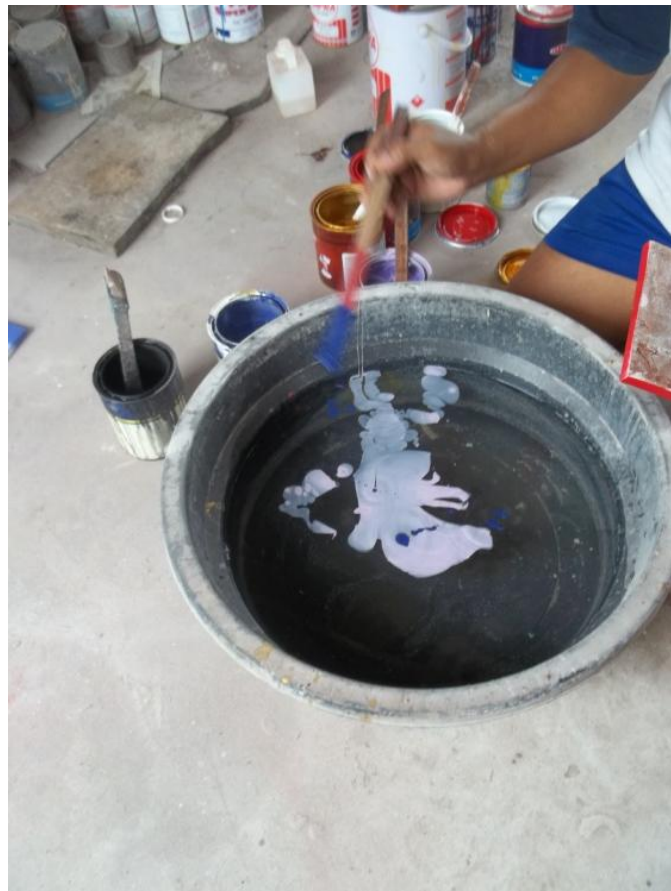

Gambar 5. Masukkan cat minyak ke dalam air dengan cepat sesuai warna keinginan kita

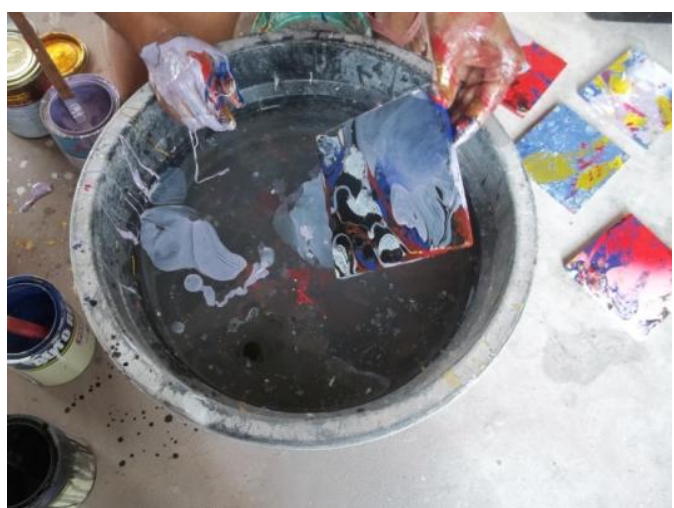

Gambar 6. Masukkan produk gerabah ke dalam air dengan gerakan memutar dan air bergelombang, setelah itu angkat gerabah mengambil ritme garis cat dalam air

\section{KESIMPULAN}

Perkembangan dunia keramik modern menuntut bentuk diversifikasi produk dimana kebutuhan akan desaindesain produk gerabah tidak hanya berbentuk silindris. Bentuk-bentuk gerabah dengan bentuk non silindris saat ini sangat diminati pasar keramik dunia. Konsumen menginginkan ada sentuhan produk yang 
kreatif dan inovatif selain bentuk-bentuk gerabah silindris.

Seiring dengan pencapaian bentukbentuk gerabah non silindris kreatif dan inovatif di sentra gerabah Pundong dan Kasongan, sangat dibutuhkan sentuhan akhir yaitu finishing yang baik dan menunjang proses kreatifitas tersebut selaras dengan trend disain. Finishing kontemporer dengan teknik painting in the water akan menjadi salah satu finishing yang mendukung kemajuan gerabah kreatif tersebut. Maka hasil dari penelitian ini merupakan jawaban dan langkah awal telah berhasil melakukan percobaanpercobaan ilmiah dimana telah ditemukan teknik cetak reproduksi gerabah yang tepat dengan komposisi tanah yang ideal dan finishing yang belum pernah diterapkan dalam produksi gerabah tradisional di sentra Pundong dan Kasongan.

Penelitian telah dilakukan sesuai target penelitian, dimana telah dapat diciptakan komposisi tanah yang baik untuk teknik reproduksi cetak gerabah non silindris. Teknik reproduksi keramik telah membantu menciptakan gerabah-gerabah inovatif, kreatif yang memiliki bentuk yang sama, tepat ukuran dan dapat diproduksi massal dengan mudah. Sehingga akan mempercepat produksi dan membantu mengatasi kekurangan atau kesalahankesalahan ukuran yang selama ini menjadi kendala jika diproduksi manual tanpa cetakan.

Penciptaan finishing kontemporer akan mempercantik bentuk-bentuk produk gerabah dan harapannya akan mampu meningkatkan nilai harga jual produk gerabah di sentra Pundong dan Kasongan. Dengan demikian akan diperoleh peningkatan produksi yang berimbas pada peningkatan ekonomi kesejahteraan pengrajin gerabah di sentra gerabah Pundong dan Kasongan.

\section{CONTOH HASIL PENELITAIAN EKPERIMEN WARNA PAINTING IN THE WATER}
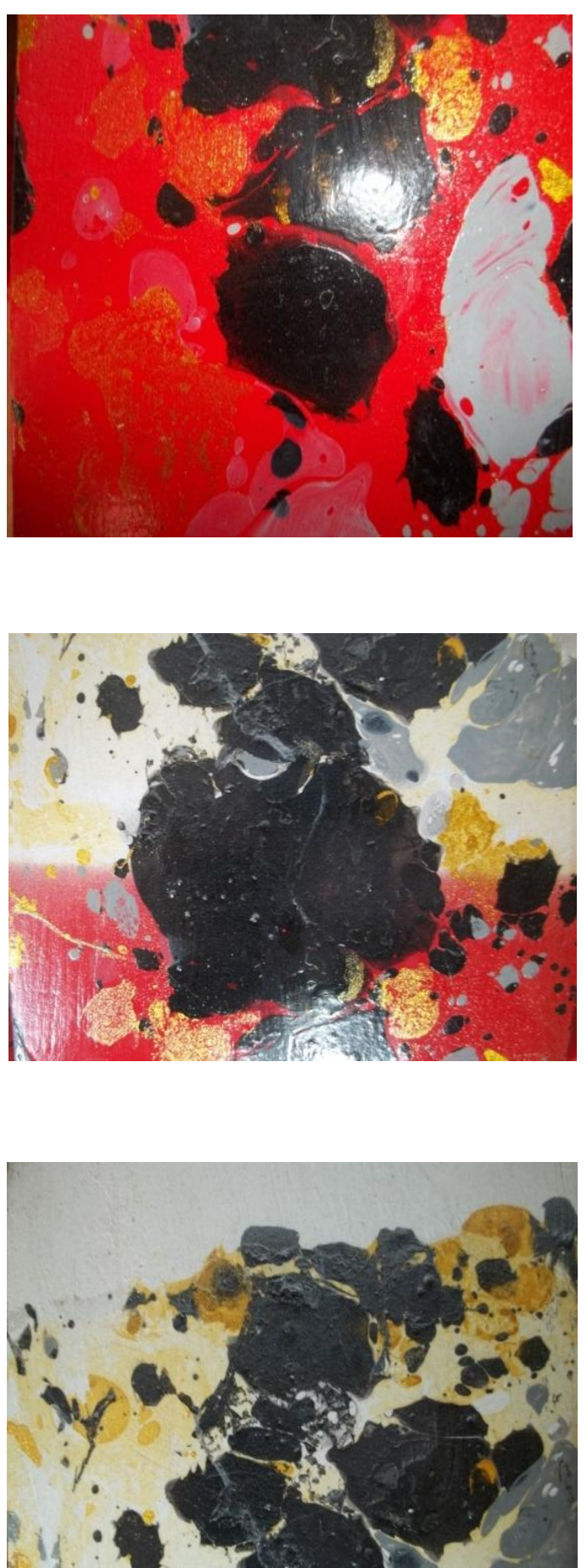

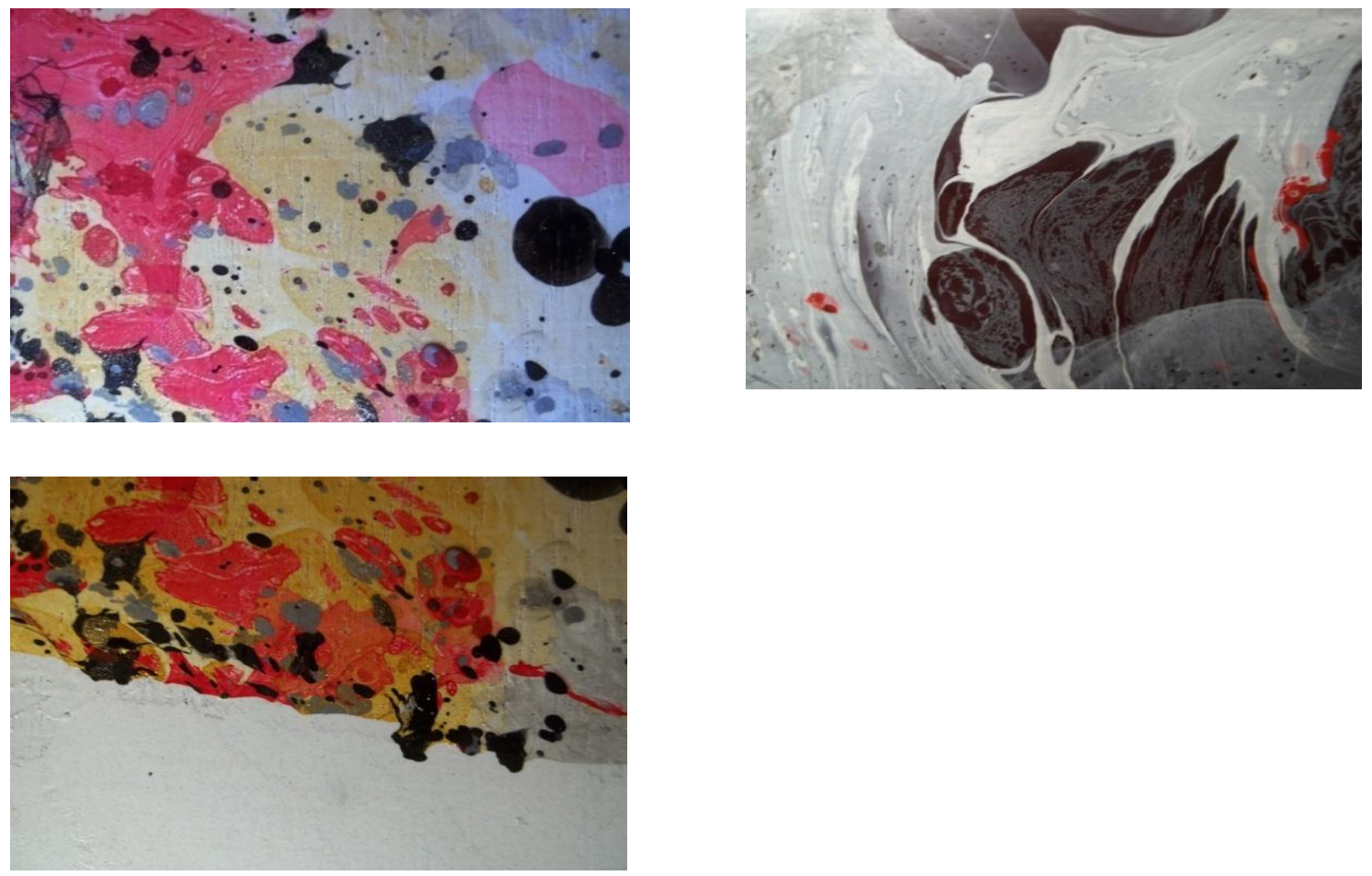

HASIL PENELITIAN FINISHING PAINTING IN THE WATER PADA PRODUK GERABAH NON SILINDRIS
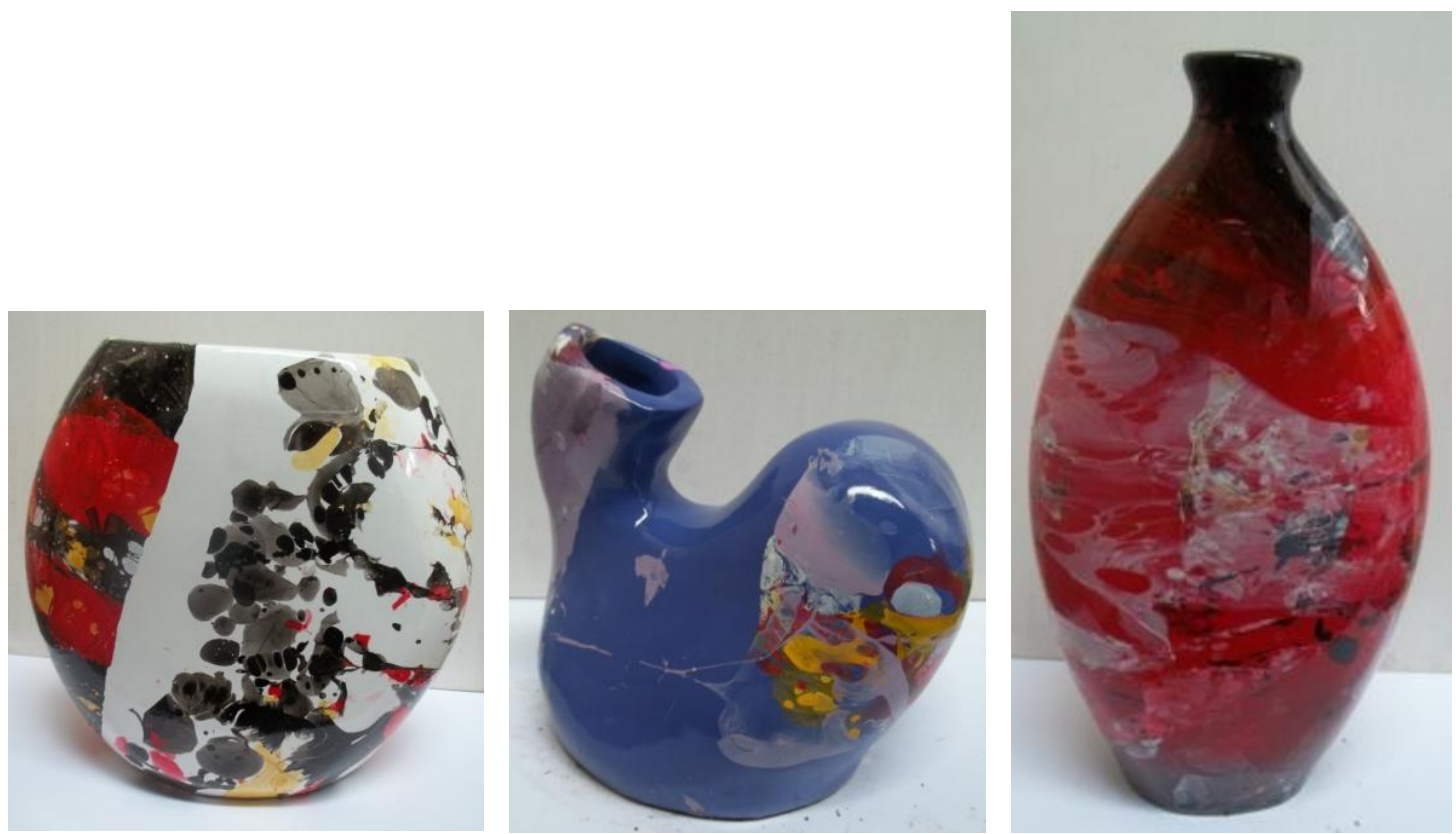

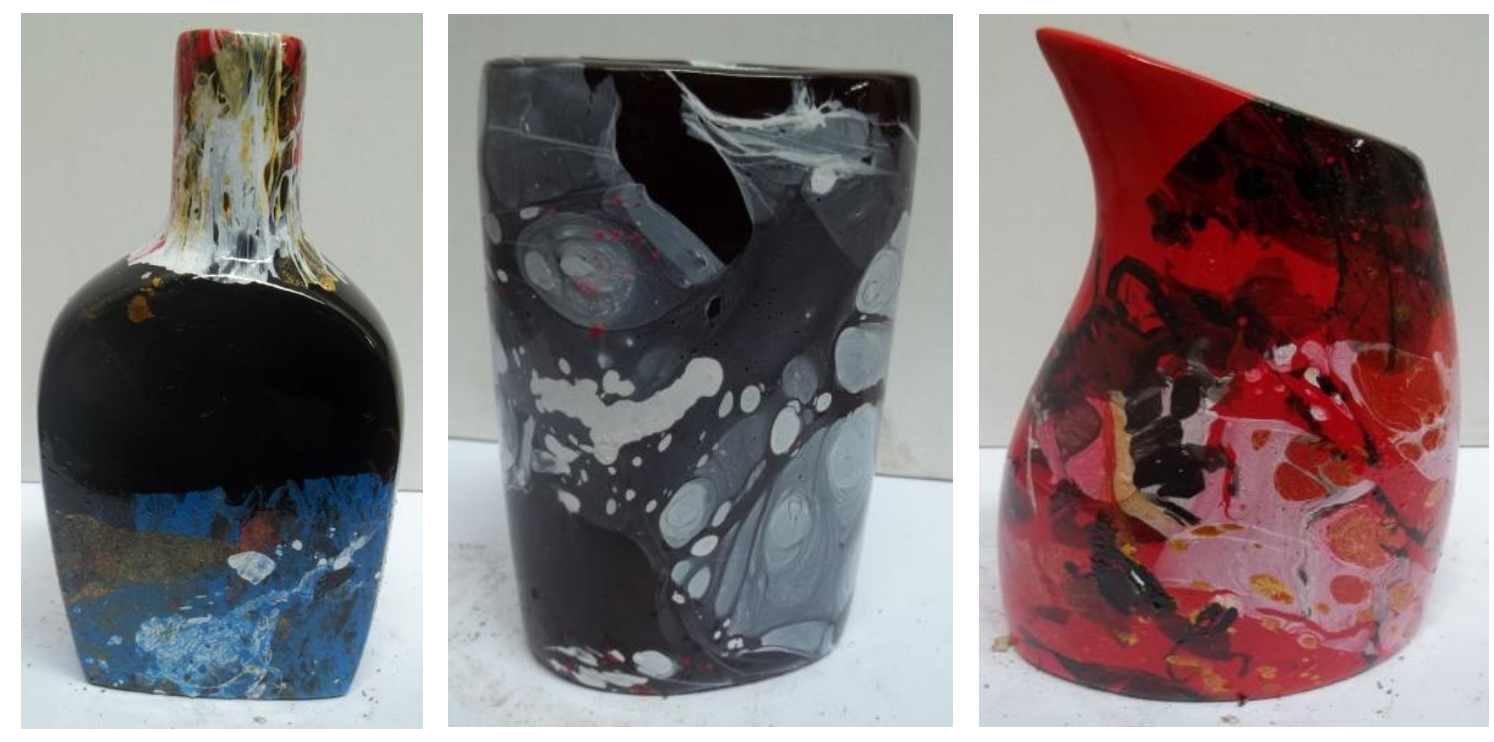

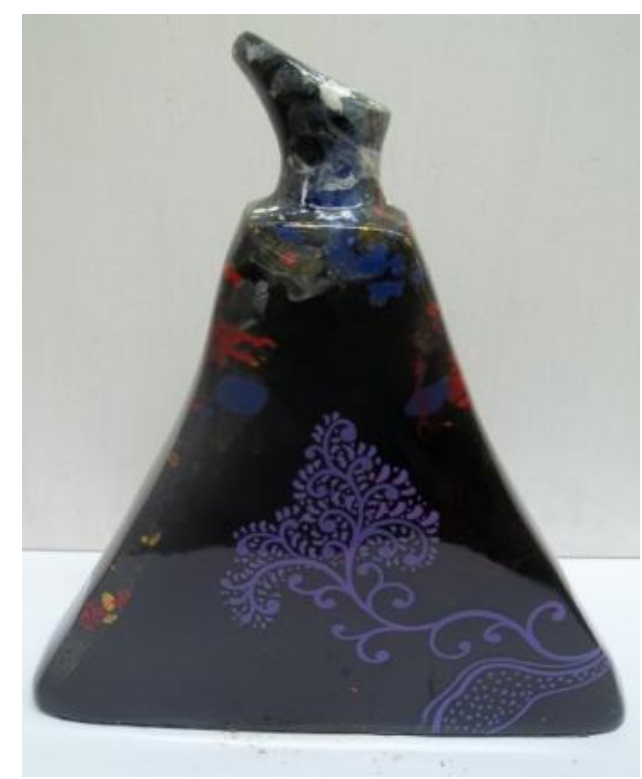

DAFTAR PUSTAKA

A.Hluch, Kevin, 2001, The Art Of Contemporary American Pottery, Krause Publications Amerika

Astuti, Ambar, 2001, Pengetahuan Keramik, Yogyakarta: Gadjah Mada University Press Yogyakarta
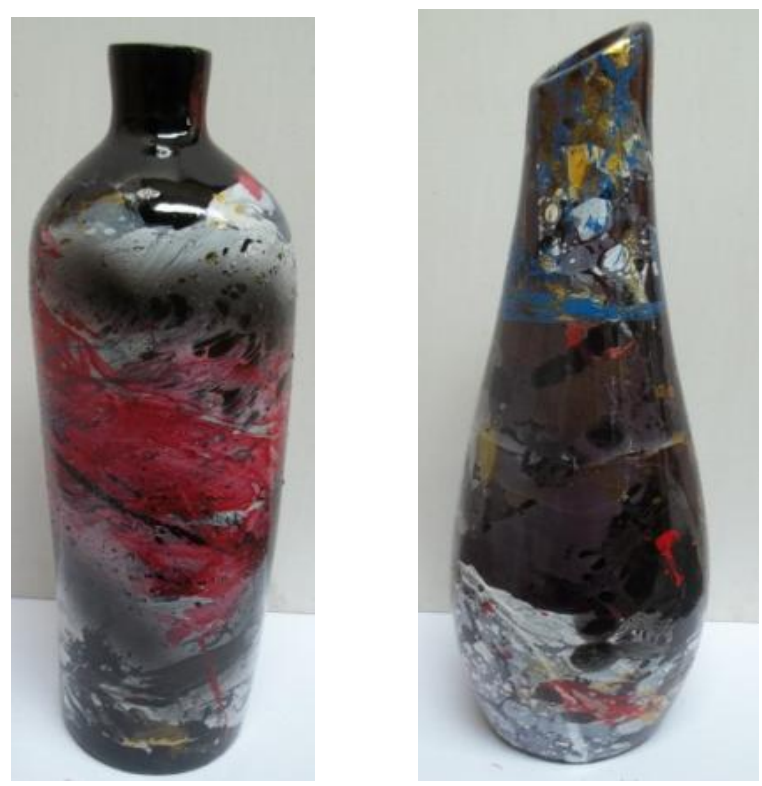

, 2008, Keramik: IImu dan Proses Pembuatannya, Jurusan Kriya, Fakultas Seni Rupa, Institut Seni Indonesia Yogyakarta

Alexander, Brian, 2001, Kamus Keramik, Jakarta, Penerbit Milenia Populer

Chavarria, Joaquim, 1994, The Big Book of Ceramics, New York, WatsonGuptil Publications 
Clark, Kenneth, 1986, The Potter's Manual, New Jersey: Chartwell Books. Inc Colbeck, John, 1987, The Technique of Pottery, London, BT Bestford Limited

Daryono, Natas Setiabudi, 2001, Pengenalan Keramik, Bandung, Indy Label

Fischer, Joseph, 1994, The Folk Art of Java, Oxford University Press, Oxford, Singapore, New York, Kualalumpur

Gustami, Saptoto, Narno S, 1985, Pola Hidup dan Produk Kerajinan Keramik Kasongan Yogyakarta, Departemen Pendidikan dan Kebudayaan Direktorat Jendral Kebudayaan Proyek Penelitian dan Pengkajian Kebudayaan Nusantara

Harsono, FX, 1992, Perkembangan Seni Rupa Kontemporer IndonesiaTinjauan Problematik, Jurnal Seni, edisi II/03-Juli 1992, Yogyakarta: BP.ISI.

Hogan, Elizabeth, 1977, Ceramic Techniques and Project, California Penerbit Lane Publishing $\mathrm{CO}$, Menlo Park
Moleong, Lexy J, 2004, Metodologi Penelitian Kualitatif, Penerbit PT Remaja Rosdakarya, Bandung

Raharjo, Timbul, 2008, Seni Kerajinan Keramik Kasongan Yogyakarta Di Era Globalisasi: Perjalanan Dari Dusun Gerabah Menjadi Sentra Seni Kerajinan Keramik Yang Mendunia, (Disertasi), Universitas Gadjah Mada, Yogyakarta

R.A. Razak, 1981, Industri Keramik, Jakarta, Balai Pustaka

Suharson, Arif, 2012, Komposisi Tanah Untuk Teknik Reproduksi, Keramik Di Sentra Gerabah Pagerjurang Klaten, Laporan Penelitian Hibah Bersaing, LPT ISI Yogyakarta

Supangkat, Jim, Sumartono, Asmudjo Jono Irianto, Rizki A. Zaelani, M. Dwi Marianto, 2000, Outlet Yogya Dalam Peta Seni Rupa Kontemporer Indonesia, Yogyakarta: Penerbit Yayasan Seni Cemeti.

Yumarta, Yardini, 1981, Keramik, Bandung, Penerbit Angkasa 